\title{
Assessment of Metformin Versus Insulin for the Treatment of Gestational Diabetes
}

\author{
ABEER B. AHMED, M.D.; MARIAM L. ABD-ELFATTAH, M.D.; RASHA E.A. KHAMEES, M.D.; \\ AHMED HASSAN, M.D. and MAHMOUD A. GREASH, M.Sc.
}

The Department of Obstetrics and Gynecology, Faculty of Medicine, Suez Canal University

\begin{abstract}
Background: Metformin is a logical treatment for women with gestational diabetes, but randomized trials to assess the efficacy and safety of its use for this condition are lacking.

Aim of Study: To compare the efficacy of oral metformin therapy versus insulin treatment in patients with gestational diabetes mellitus in term of Maternal glycemic control, Maternal outcome and Fetal outcome.

Patients and Method: A total of 156 patients who have the diagnosis of gestationl diabetes were enrolled after fulfilling certain inclusion and exclusion criteria. They were randomly assigned to two groups of treatment with either insulin or metformin. Serial ultra-sound examination and blood glucose level were assessed at enrolment and at follow-up visits. The outcomes were fetal and maternal outcomes.

Results: Of the 78 patients at each group $89.7 \%$ of patients using metformin were compliant to its use while only $39.7 \%$ who received insulin therapy were compliant to it ( $p$-value $0.015)$, neonatal hypoglycemia was associated more with insulin group than metformin group $(7.7 \%$ vs. $0.0 \%, p$-value 0.028 ). The rates of other outcomes did not differ significantly between the groups. There were no serious adverse events associated with the use of metformin.

Conclusion: Oral metformin therapy is an effective and safe treatment option for women with gestational diabetes who meet the criteria for starting insulin, and that metformin is more acceptable than insulin. But further follow-up data are needed to establish long-term safety regarding the pregnancy outcome.
\end{abstract}

Key Words: Metformin - Oral therapy - Gestational diabetes.

\section{Introduction}

MATERNAL hyperglycemia is associated with an increased risk of perinatal complications, especially fetal macrosomia, which increases the risk of labor complications such as shoulder dystocia and the need for caesarean sections, and perinatal

Correspondence to: Dr. Rasha E. Khamees, E-Mail: rashakhamiss@yahoo.com morbidity, such as birth asphyxia. Maternal hyperglycemia is also associated with an increased rate of gestational hypertension and pre-eclampsia $[1,2]$

Active management of GDM has been found to reduce the incidence of macrosomy and perinatal morbidity $[\mathbf{1 , 3}]$. Diet and lifestyle counseling are the corner stones in the treatment of gestational diabetes. If normoglycaemia is not attained with diet, insulin is traditionally considered to be the first-line medical treatment. Detailed guidance is needed to ensure the safe self-administration of insulin and to avoid hypoglycemia. Safe and effective oral therapy would be more acceptable and simpler for women with GDM [3].

Metformin lowers blood glucose concentrations by inhibiting gluconeogenesis in the liver, and by increasing glucose uptake in skeletal muscles and adipocytes [4]. It does not stimulate insulin production and is therefore not associated with the risk of hypoglycemia $[5,6]$. Also it improves insulin sensitivity, probably by activating AMP kinase, and is not associated with weight gain or hypoglycemia [7]. Although metformin crosses the placenta, [8] no increased rate of congenital malformations or other adverse fetal outcomes have been reported in studies on women with polycystic ovary syndrome (PCOS) treated with metformin throughout pregnancy [9].

This study was performed to conclude that if perinatal outcomes in gestational diabetics women would be similar for both treatments or revealed better by metformin, women would consider oral metformin a more acceptable treatment than injectable insulin. 


\section{Patients and Methods}

This randomized clinical trial was carried out in the outpatient clinic and inpatient department of the Obstetrics and Gynecology Department of Suez Canal University Hospital from Feb. 2013 to Feb. 2014. After study approved by the hospital's clinical committee, informed written consent was obtained from all 156 patients whom included in the study according to inclusion and exclusion criteria as follows:

\section{Inclusion criteria:}

1- The age group between 23 and 45 years old.

2- The diagnosis of gestational diabetes mellitus according to American Diabetes Association [ADA] criteria of diagnosis using $100 \mathrm{gm}$ oral glucose tolerance test as following [10]

- Fasting serum glucose concentration exceeding $95 \mathrm{mg} / \mathrm{dL}$.

- 1-hour serum glucose concentration exceeding $180 \mathrm{mg} / \mathrm{dL}$.

-2-hour serum glucose concentration exceeding $155 \mathrm{mg} / \mathrm{dL}$.

-3-hour serum glucose concentration exceeding $140 \mathrm{mg} / \mathrm{dL}$.

3-Pregnant with a single fetus with gestational age between 20 and 33 weeks of gestation.

4- After lifestyle intervention consisting of advice about diet and exercise.

Exclusion criteria were Pre-gestational diabetes mellitus, Contraindication to metformin, as renal impairment, chronic liver disease or severe gastrointestinal symptoms, Fetal anomaly, Gestational hypertension or preeclampsia, Fetal growth restriction or Ruptured membranes.

Sampling method: We have performed the 50 gram oral glucose tolerance screening test to all pregnant attending outpatient clinic of Obstetrics and Gynecology Department at or after 18 weeks gestation, then patients who had result $\geq 140 \mathrm{mg} / \mathrm{dl}$ were asked to perform the 100 gram oral glucose tolerance test, then according to ADA criteria of diagnosis we identify those who have the diagnosis of gestational diabetes mellitus.

After that they were given health education regarding diet and exercise and asked to repeat (FBS, RBS) after 1 week, but if they still have hyperglycemia they were included in our study.

Data collection was through full medical history, complete physical examination, transabdominal ultrasound was done to every participant to exclude any fetal abnormalities or congenital anomalies in order not to blame the drugs for causing such anomalies, Then, HbA1c, FBS and RBS were done as a basic lab for every participant at enrolment at the study.

After that patients were randomized by numbering of cases and allocating patients with odds numbers to metformin group and patients with even numbers to insulin group.

First group was treated by oral metformin therapy starting with 500mg per day and then reassess blood glucose level daily with the possibility of increasing the dose up to $2500 \mathrm{mg}$ per day, when euglycemic state achieved we would repeat (FBS and RBS) after 1 week then every 2 weeks till delivery.

Second group was treated by injectable insulin according to body weight (0.6-0.9 units per kg per day) depending on the trimester of pregnancy; $0.6 \mathrm{u} / \mathrm{kg}$ for the first trimester, $0.7 \mathrm{u} / \mathrm{kg}$ for the $2 \mathrm{nd}$ trimester and $0.9 \mathrm{u} / \mathrm{kg}$ for the 3 rd trimester [11] or adjusting the daily dose after calculating the total regular insulin required over 48 hours admission to internal unit according to sliding scale method and then dividing it into two third by daytime and one third at night in the form of mixed insulin, when euglycemic state achieved we would repeat (FBS and RBS) after 1 week then every 2 weeks till delivery.

Throughout pregnancy we followed-up the patients by trans-abdominal ultrasound for detection of any abnormalities such as macrosomia, polyhydramnious and follow-up investigations of diabetes mellitus:

- (HbA1c) at enrolment, after 2 months of therapy and before delivery.

- (FBS, RBS) after 1 week of therapy then every 2 weeks till time of delivery.

Patients received their treatment till timing of deliveries, which was 39 weeks for those who have previous caesarian section or when labor pain start with those who have previous vaginal deliveries or primigravida. All patients have received $24 \mathrm{mg}$ dexamethasone at 32 weeks of gestation.

At delivery, complications of pregnancy, the indication for delivery, mode of delivery and neonatal complications were recorded.

Through the study we have assessed maternal outcomes; Maternal hypoglycemia, Maternal complication as gestational hypertension or pre-eclampsia, Patient compliance to her treatment and 
also Patients glycemic control was followed-up by: FBS, Post prandial 1 hour and 2 hours every 2 weeks, HbA1c at the start of the work and then after 2 monthes and before delivery.

Fetal outcomes assessed by: Follow-up transabdominal ultrasonography for assessment of fetal weight and amniotic fluid index, gestational age at delivery, Apgar score was assessed 1 and 5 minutes after birth, Neonatal respiratory distress, Macrosomia and birth injuries, Neonatal hypoglycemia, congenital anomalies, I.U.F.D. or neonatal death and Admission to NICU.

The data was coded, organized and the final study results was stated using the SPSS (statistical package for social sciences) version 20 and data was presented through tables and graphes.

As appropriate numerical data was expressed as mean with or without SD and categorical data was expressed as number \%. Student $t$-test was used to test statistical significance of continuous variable between two groups, while chi-square test was used for categorical variables.

Statistical significance was considered at $p$ value $<0.05$ and highly significance at $p$-value $<0.01$.

\section{Results}

This study included 78 patients in each group who have the American Diabetes Association criteria for diagnosis of gestational diabetes, there was insignificant difference between both groups regarding baseline characteristics at enrollment at the study, the range of age in Metformin group was $24-43$ years (mean $\pm \mathrm{SD}=31.8 \pm 5.1$ ), while those in Insulin group were with range of age 2343 years (mean $\pm \mathrm{SD}=30.6 \pm 4.5)$. According to weight (mean $\pm \mathrm{SD}$ ) in Metformin group was $78.6 \pm 7.4$ and in Insulin group was $78.1 \pm 6.8$. In Metformin group glycated hemoglobin was with (mean \pm SD) $5.34 \pm 0.540$ while in Insulin group was $5.37 \pm .58$. Only $4(5.12 \%)$ of the Metformin group have Family history of GDM while 10 $(12.8 \%)$ of the insulin group have this history, none of the patients of both groups had chronic hypertension.

None of the most important items in the obstetric history show significant difference between both groups, it shows that there were 9 patients with a previous history of gestational DM among Metformin group, 20 patients with history of cesarean delivery among insulin group, also only 1 patient of the metformin group had previous history of infant with congenital anomalies and only 1 patient of the Insulin group had previous history of I.U.F.D. about the mode of delivery $75.6 \%$ of patients in Metformin group delivered by vaginal delivery while $62.8 \%$ patients in the insulin group did.

No significant difference between the two groups regarding the associated maternal hypertensive complications. There were no cases of preeclampsia in both groups.

The amniotic fluid index Mean \pm SD in Metformin group and Insulin group was respectively $13.3 \pm 3.0$ and $13.3 \pm 2.9$. In insulin group there were 9 patients with fetal weight of more than $4000 \mathrm{gm}$ before delivery while only 7 patients in the Metformin group, with no significant difference (Table

There was no significant difference in the maternal glycemic control between the two groups and also shows no significant difference in the risk of development of hypoglycemia between patients used metformin and those who used insulin (Table

There was significant difference between the two groups in maternal compliance to treatment as $89.7 \%$ of patients using metformin were compliant to the use of it while only $39.7 \%$ who received insulin therapy were compliant to it (Table $3)$. There was no significant relation between the two groups regarding the primary neonatal outcome; Gestational age at birth, Birth weight, Preterm birth, 1 minute Apgar score and 5 minute Apgar score (Table 4).

Table (5) shows significant difference regarding the risk of developing neonatal hypoglycemia as 6 of the neonates developed hypoglycemia in the insulin group. No cases of birth trauma or congenital anomalies reported in any group.

Table (1): Follow-up ultrasound at time of delivery.

\begin{tabular}{lccc}
\hline Outcome & $\begin{array}{c}\text { Metformin } \\
\text { Group } \\
(\mathrm{N}=78)\end{array}$ & $\begin{array}{c}\text { Insulin } \\
\text { Group } \\
(\mathrm{N}=78)\end{array}$ & $\begin{array}{c}p \text { - } \\
\text { value }\end{array}$ \\
\hline $\begin{array}{l}\text { Amniotic fluid indece: } \\
\quad \text { Mean } \pm \text { SD }\end{array}$ & $13.3 \pm 3.0$ & $13.3 \pm 2.9$ & 1.0 \\
$\begin{array}{l}\text { Polyhydramnious: } \\
\quad \text { No. }(\%)\end{array}$ & $4(5.12 \%)$ & $4(5.12 \%)$ & 1.0 \\
$\begin{array}{l}\text { Expected fetal } \\
\text { weights before } \\
\begin{array}{l}\text { delivery } \geq 4000 \text { gm: } \\
\quad \text { No. }(\%)\end{array}\end{array}$ & & & \\
\hline
\end{tabular}

Significant $p$-value $<0.05$. 
Table (2): Comparison between maternal glycemic controls in both groups.

\begin{tabular}{cccc}
\hline & Metformin & Insulin & \\
Outcome & Group & Group & $p$ value \\
& $(\mathrm{N}=78)$ & $(\mathrm{N}=78)$ & \\
\hline
\end{tabular}

\begin{tabular}{|c|c|c|c|}
\hline $\begin{array}{l}\text { Glycemic control from } \\
\text { randomization until } \\
\text { delivery (Mean } \pm S D) \text { : } \\
\text { - Capillary glucose } \\
\text { level after an } \\
\text { overnight fast } \\
(\mathrm{mg} / \mathrm{dl})\end{array}$ & $90.6 \pm 10.5$ & $93.6 \pm 18.8$ & 0.22 \\
\hline $\begin{array}{l}\text { - } 1 \mathrm{hr} \text { postprandial } \\
\text { capillary glucose } \\
\text { level }(\mathrm{mg} / \mathrm{dl})\end{array}$ & $136.6 \pm 16.9$ & $141.6 \pm 5.8$ & 0.08 \\
\hline $\begin{array}{l}\text { - Glycoselated } \\
\text { hemoglobin at wk } \\
36-37(\%)\end{array}$ & $5.8 \pm 0.9$ & $5.7 \pm 0.9$ & 0.82 \\
\hline
\end{tabular}

Patients with

euglycemic state from

randomization until

delivery

\begin{tabular}{clll} 
- No. (\%) & $67(85.9 \%)$ & $66(84.6 \%)$ & 0.82 \\
Maternal hypoglycemia & $0(0.0 \%)$ & $1(1.3 \%)$ & 1.0 \\
\hline
\end{tabular}

Significant $p$-value $<0.05$.

Table (3): Maternal compliance to treatment.

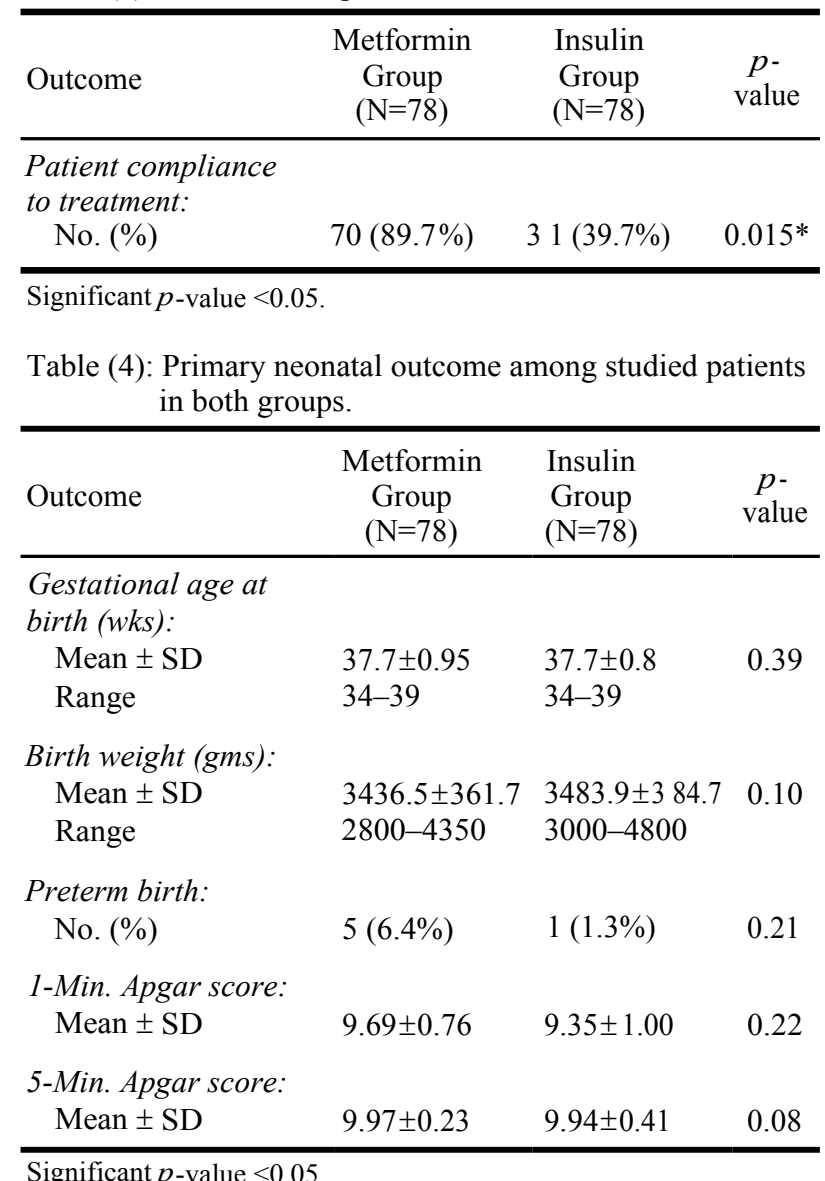

Significant $p$-value $<0.05$.
Table (5): Comparison between the two groups regarding neonatal complications.

\begin{tabular}{lccc}
\hline Outcome & $\begin{array}{c}\text { Metformin } \\
\text { Group } \\
(\mathrm{N}=78)\end{array}$ & $\begin{array}{c}\text { Insulin } \\
\text { Group } \\
(\mathrm{N}=78)\end{array}$ & $\begin{array}{c}p \text { - } \\
\text { value }\end{array}$ \\
\hline $\begin{array}{l}\text { Neonatal hypoglycemia } \\
(<45 \mathrm{mg} / \text { dl) })\end{array}$ & & & \\
$\quad$ No. $\%)$ & $0(0.0 \%)$ & $6(7.7 \%)$ & $0.028^{*}$ \\
$\begin{array}{l}\text { Respiratory distress: } \\
\quad \text { No. }(\%)\end{array}$ & $2(2.6 \%)$ & $4(5.1 \%)$ & 0.41 \\
$\begin{array}{l}\text { Admission to NICU: } \\
\text { No. }(\%)\end{array}$ & $2(2.6 \%)$ & $4(5.1 \%)$ & 0.41 \\
\hline Significant $p$-value $<0.05$. & & &
\end{tabular}

\section{Discussion}

This study is randomized clinical trial study to determine the efficacy of oral metformin therapy instead of injectable insulin as a better management of diabetes in patients with gestational diabetes mellitus.

The study was carried out in the Outpatient Clinic and inpatient unit of the Obstetrics and gynecology Department of Suez Canal University Hospital, through studying 156 patients with age between 23 and 44 years presented with criteria of gestational diabetes mellitus according to American Diabetic Association (ADA) and according to inclusion and exclusion criteria as mentioned before in chapter of patients and methods.

Baseline characteristics of women in the metformin and insulin groups are nearly similar in mean age, mean weight and history of previous GDM, similarity of these factors decrease the chance of bias.

History of Previous gestational diabetes is one of the most important risk factors but show also insignificant deference between the two groups where $9(11.5 \%)$ patients in the metformin group have this history versus $7(9.0 \%)$ patients of the second group taking insulin therapy. At the MIG trial by Rowan et al., 2008, 25.9\% of patients at metformin group had previous gestational diabetes versus $21.9 \%$ of patients at insulin group [12]

In our study; hypertensive disorders associated with gestational diabetic patients treated with metformin was $6.4 \%$ while with patients treated by insulin was $11.5 \%$ in the form of gestational hypertension, but no cases reported to have preeclampsia, results of Rowan et al., [12] and Niromanesh et al., [13] matched with our results regarding associated gestational hypertension in nearly 
similar percentage of cases, but Rowan et al., reported cases of preeclampsia, this difference might have occurred due to larger sample size as they have studied 733 patients versus 158 patients in our study, they found that pre-eclampsia developed in 5.5\% in patient treated with metformin vs. $7 \%$ in patient treated with insulin [12]

so most of the finding in our study and other studies is that hypertensive disorders can associate gestational diabetes, irrespective to type of treatment, but although there is insignificant difference between its occurrence and the type of drug used, yet higher percentage of associated hypertensive disorders noted with insulin therapy, metformin has reduction effect on cardiovascular disease.

In our study; metformin achieved glycemic control in $85.9 \%$ of patients while insulin achieved glycemic control in $84.6 \%$ of patients, which is insignificant difference in one of the most important outcomes discussed in this study, Another study by Dasari et al., [14] reported that $89.5 \%$ of patients treated with metformin achieved glycemic control which support our findings, as there are no doubt that metformin as a drug is highly efficient in controlling blood glucose level without causing overt hypoglycemia having been in clinical use for over 50 years.

In this study maternal hypoglycemia occurred only in patients treated with insulin therapy in about $1.3 \%$ of cases but did not occur with metformin therapy, the hypoglycemia reported with this case was due to administrating insulin injection while fasting which is contraindicated, Dasari et al., [14] also reported that none of the patients treated with metformin suffered hypoglycemia, as metformin lowers blood glucose concentrations without causing overt hypoglycemia. On the other hand; Balani et al., 2012 found that $6.5 \%$ of patients treated with metformin developed hypoglycemia that may have resulted from higher doses used by some patients as it was accepted up to $3 \mathrm{gm}$ daily in there study [15].

In our study, there is significant difference between the two drugs regarding patients compliance to treatment as $89.7 \%$ of patients treated with metformin reported there compliance to there treatment and regularity in administrating it and would take it rather than insulin if they developed gestational diabetes in further pregnancies, while only $39.7 \%$ of patients treated with insulin were compliant with there treatment while the rest of patients treated with it reported there restlessness due to daily injections and continuous fear of hypoglycemic coma, so they were not taking it regularly, This was matched with Rowan et al., results [12].

In our study there was no significant difference in incidence of occurrence of polyhydramnious which was about $5.12 \%$ for each group. According to our knowledge; no study has demonstrated the relationship between amniotic fluid index and administrating metformin or insulin treatment. It was associated mainly with cases of uncontrolled diabetes.

Caesarian section rate increased from 14. 1\% to $24.4 \%$ in patients who received metformin but this increase in rate was more with the insulin therapy which increased from $25.6 \%$ to reach $37.2 \%$, the cause of this increased rate of caesarian section is due to macrosomia and fear of shoulder dystocia and traumatic deliveries due to disproportionate growth of infant of diabetic mother. Another study by Rowan et al., [12] show relatively similar results $(22.9 \%)$ in metformin group versus $(23.2 \%)$ in insulin group. Higher incidence of C.S deliveries with insulin group might have been due to noncompliance to treatment which might have cause hyperglycemia and macrosomia.

Regarding fetal macrosomia, it developed in $9 \%$ of patients treated with metformin versus $11.5 \%$ of patients treated with insulin in our study, which is insignificant, Rowan et al., found that $19.3 \%$ of diabetic mother treated with metformin had macrosomic babies versus $18.6 \%$ of those treated by insulin therapy [12]. Another study by Hassan et al., found that fetal macrosomia occurred in $10.67 \%$ of patients treated with metformin group versus $18.67 \%$ of those treated with insulin therapy, [16] but Nicholson et al., found that $19 \%$ of babies were macrosomic and no deference in both groups [17] macrosomia developed mainly with patients with uncontrolled diabetes as maternal hyperglycemia lead to fetal hyperglycemia and then fetal hyperinsulinemia which is anabolic hormone leading to macrosomic baby $[\mathbf{1 , 2}]$.

According to our study; there is significant difference between the two groups regarding neonatal hypoglycemia, it have not occurred with patients treated with metformin therapy but occurred in $7.7 \%$ of those treated by insulin therapy, our finding was supported by Hassan et al., [16], Rowan et al., [12], Nicholson et al., [17] and finally Ija"s et al., found that neonatal hypoglycemia is more prominent in those patients treated with insulin in comparison with those treated by metformin $14 \%$ vs. $8.5 \%$. [12] neonatal hypoglycemia 
mostly arise in hyperglycemic cases as maternal hyperglycemia leads to neonatal hyperglycemia and then hyperinsulinemia which cause neonatal hypoglycemia at delivery because of deprivment of glucose source from maternal circulation [11].

In our study neonatal respiratory distress occurred in $2.6 \%$ of patients treated by metformin versus $5.1 \%$ of those treated by insulin, so the difference is insignificant. It was nearly similar to the study of Rowan et al., [12] and Hassan et al., 2012 found that neonatal respiratory distress has occurred in $4 \%$ of cases of both groups, [16] But Niromanesh et al., found that respiratory distress occurred more with metformin group by about $6.3 \%$ in comparison with insulin $2.5 \%$ [13] .

In this study we have done congenital anomaly scan before starting medication as a matter of exclusion and inclusion criteria for all our participants in order not to blame the drugs in causing such anomalies which may arise from hyperglycemia itself and not from the drugs, then after delivery we screened again to announce the effect of the drugs in causing any congenital anomalies but we have not found any anomalies in our participants of both groups, as Dasari et al., [14] but Rowan et al reported associated anomalies in 3.03\% of babies in the group treated by metformin versus $4.86 \%$ in the other group, which might have aroused from the toxic effect of hyperglycemia itself and not related to the drugs [12]. Because metformin crosses the placenta, there have been concerns about raised possible adverse effects in the developing fetus or in later life. But, in accordance with other studies, we found no teratogenicity or increased anomaly rates.

In our study we noticed that preterm delivery were more with patients treated with metformin than with those treated with insulin $6.4 \%$ versus $1.3 \%$ but still the difference between the two groups is insignificant, this finding was noticed by many other studies like Rowan et al., $7.2 \%$ versus $4.1 \%$, [12] Nicholson et al., $12 \%$ vs. $8 \%$, [12] and Niromanesh et al., $11.3 \%$ vs.5\% respectively, [13] but none of these studies has reasonable explanation. Preterm births could be due to chance or to an unrecognized effect of metformin on the labor process. The increased rate of preterm birth was not associated with higher rates of other complications, probably because the difference between the two groups in mean gestational age at delivery was statistically insignificant. The rationale was; if metformin had any unanticipated adverse effect on fetal growth or well-being, there would be more iatrogenic preterm births, which has not occur, the frequency of preterm birth was higher in the metformin group but spontaneous rather than iatrogenic

There are no significant difference between the two groups regarding evaluation of new born after 1 and 5 minutes by Apgar score, where the Apgar score after 1 minute of delivery ranged between (7-10) with Mean \pm SD $(9.69 \pm 0.76)$ with metformin therapy versus $(9.35 \pm 1.00)$ for the insulin group and after 5 minutes it became $(9.97 \pm 0.23)$ versus $(9.94 \pm 0.41)$ for the metformin and insulin groups respectively ranging also between (7-10). Only 5 babies have Apgar score (7) at 1 minute evaluation which becomes only 1 baby after 5 minutes evaluation due to neonatal resuscitation, this decreased score is mainly due to associated respiratory distress, hypoglycemia and prematurity. Rowan et al. found that Apgar score $\geq 7$ was associated with $(0.8 \%)$ with metformin therapy versus $(0.3 \%)$ with insulin therapy [12].

In our study 2 (2.6\%) of the babies of metformin group required NICU admission due to respiratory distress and prematurity versus $4(5.1 \%)$ of the babies of the insulin group, one of them admitted due to respiratory distress and the other 3 babies admitted duo to neonatal hypoglycemia. Rowan et al., reported much higher percentage for NICU admission (18.7\%) versus $(21.1 \%)$ for metformin and insulin respectively, [12] this high incidence may be due to larger sample size, but no reported cases of IUFD or neonatal death.

Strengths of this trial are that it was performed within routine clinical practice and included the spectrum of women with a diagnosis of gestational diabetes mellitus. A weakness is that treatment was open-label, since blinding was not considered practical or ethical. A methodologic limitation is that we used a superiority design to assess whether insulin was superior to metformin and have accepted rather than proved the null hypothesis (that there is no difference between treatments).

We found no significant increase in a composite measure of neonatal complications or primary maternal outcomes among women with gestational diabetes mellitus who were randomly assigned to metformin as compared with those who were assigned to insulin.

There was less severe hypoglycemia in the infants of mothers on metformin. Preterm birth was more common in the metformin group, but there was no increase in other complications. Women who used metformin were more likely to say they would use metformin in a subsequent pregnancy than were women on insulin. 
In conclusion oral metformin therapy is an effective and safe treatment option for women with gestational diabetes mellitus who meet the usual criteria for starting insulin, and that metformin is more acceptable to women with gestational diabetes mellitus than is insulin. But further follow-up data are needed to establish long-term safety regarding the pregnancy outcome.

\section{References}

1- LANGER O., YOGEV Y., MOST O. and XENAKIS E.M.: Gestational diabetes: The consequences of not treating. Am. J. Obstet. Gynecol., 192: 989-97, 2005.

2- METZGER B.E., LOWE L.P., DYER A.R., TRIMBLE E.R., CHAOVARINDR U., et al.: Hyperglycemia and adverse pregnancy outcomes. N. Engl. J. Med., 358: 19912002,2008

3- SPAULONCI C.P., BERNARDES L.S., TRINDADE T.C., ZUGAIB M. and FRANCISCO R.P.: Randomized trial of metformin vs insulin in the management of gestational diabetes. Am. J. Obstet. Gynecol., 209: e1-e7.: 34, 2013.

4- FORETZ M., GUIGAS B., BERTRAND L., POLLAK M. and VIOLLET B.: Metformin: From mechanisms of action to therapies. Cell. Metab., 20: 953-66, 2014.

5- WIERNSPERGER N.F. and BAILEY C.J.: The antihyperglycaemic effect of metformin: Therapeutic and cellular mechanisms. Drugs., 58 (Suppl 1): 31-9. Discussion, 7582, 1999.

6- DEFRONZO R.A.: Pharmacologic therapy for type 2 diabetes mellitus. Ann. Intern. Med., 131: 281-303, 1999.

7- ZHUO Z., WANG A. and YU H.L.: Effect of metformin intervention during pregnancy on the gestational diabetes mellitus in women with polycystic ovary syndrome: A systematic review and meta-analysis. J. Diabetes. Res., 381231, 2014.

8- CASSINA M., DONÀ M., DI GIANANTONIO E., LITTA P. and CLEMENTI M.: First-trimester exposure to met- formin and risk of birth defects: A systematic review and meta-analysis. Hum. Reprod. Update, 20: 656-69, 2014.

9- GILBERT C., VALOIS M. and KOREN G.: Pregnancy outcome after firsttrimester Exposure to metformin: A meta-analysis. Fertil. Steril., 86: 658-63, 2006.

10- American Diabetes Association. Diagnosis and classification of diabetes mellitus (Position Statement). Diabetes Care, 32 (Suppl. 1): S62-S67, 2009.

11- FERNANDO A., SHIRISH N. and AMARNATH G.: Practical guide to High-risk pregnancy \& delivery 3 rd edition; Section 2, Chapter 17: 456, 2009.

12- ROWAN J.A., HAGUE W.M. and GAO W.: Metformin versus insulin for the treatment of gestational diabetes. N. Engl. J. Med., 358: 2003-15, 2008.

13- NIROMANESH S., AZIN A., FATEMEH R., NOOSHIN A., SANAZ M. and SOHEILA A.: Metformin compared with insulin in the management of gestational diabetes mellitus: A randomized clinical trial. Diabetes Research and Clinical Practice, 98: 422-429, 2012.

14- PAPA DASARI and SYED H.: Maternal and Fetal Outcome in Gestational Diabetes Mellitus (GDM) Treated with Diet and Metformin. The Open Conference Proceedings Journal, 2: 59-63, 2011.

15- JYOTI BALANI, STEVE H., ANTOINETTE J. and HASSAN S.: Pregnancy outcomes after metformin treatment for gestational diabetes: A case-control study. Obstet. Med., 5: 78, 2012.

16- HASSAN J.A., KARIM N. and SHEIKH Z.: Metformin prevents macrosomia and neonatal morbidity in gestational diabetes. Pak. J. Med. Sci., 28 (3): 384-389, 2012.

17- NICHOLSON W., BOLEN S., WITKOP C.T., et al.: Benefits and risks of oral diabetes agents compared with insulin in women with gestational diabetes: A systematic review. Obstet. Gynecol., 113: 193-205, 2009.

18- IJÄS H., VÄARÄS MAKI M., MORIN-PAPUNEN L., KERAVUO R., EBELING T., SAARELA T. and RAUDASKOSKI T.: Metformin should be considered in the treatment of gestational diabetes: A prospective randomised study. BJOG, 118: 880-885, 2011. 


\section{تقييم الميتفورمين مقابل الإنسولين لعلاج سكر الحمل}

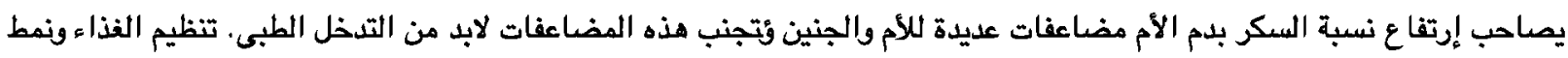

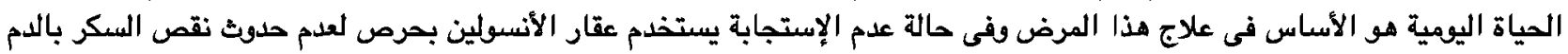
فيؤدى إلى غييوبة نقص السكر بالإضافة لآثار الحقن اليومى الجانبية. عقار الميتفورمين بالفم هو الهنطقى لهده الحالات ولكن هنالك إفتقار اللدراسات التى تقيم إستخدامه.

هدف البحث: ومن هنا جاءت فكرة هذه الدراسة لمقارنة عقار الإنسولين بعقار الميتفومين لعلاج سكر الحمل.

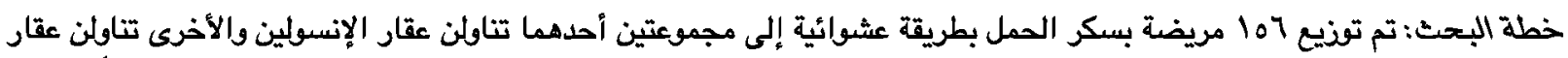

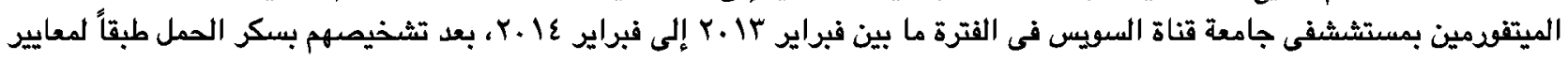

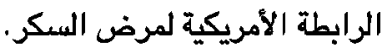

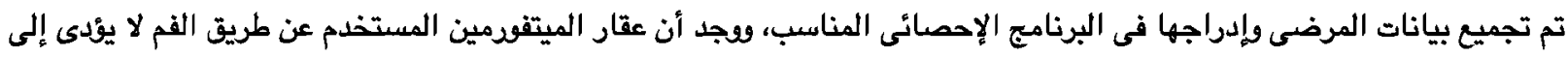

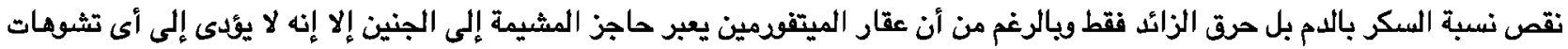

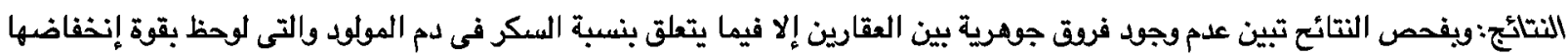

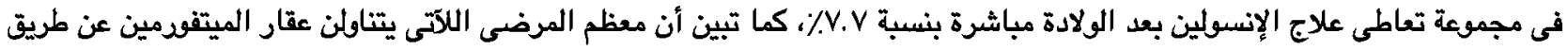

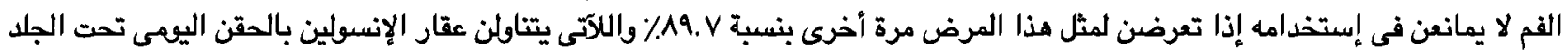

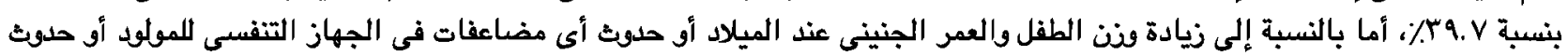

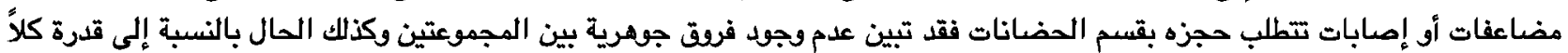
العقارين على ظبط نسبة السكر بالدم وطريقة الولادة وزيادة السائل الأمنيوسى وأخيراً حدوث إرتفاع بضغط التهان الدم. الإستتاجات: إذا كان لعقار الميتفومين عن طريق الفم أثر علاجى مساوى أو أفضل من حقن الإنسولين يومياً تحت الجلد فسيكون هو

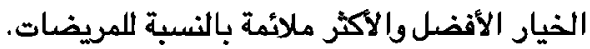

